NOTAS

\title{
APUNTES SOBRE EL CHOQUE CULTURAL ENTRE EL MUNDO OCCIDENTAL Y EL ISLÁMICO \\ H.C.F. Mansilla*
}

Aunque en forma mitigada por comparación a décadas pasadas, prevalece aún en América Latina, y no sólo en círculos izquierdistas, un sentimiento colectivo de solidaridad con el resto del Tercer Mundo. Pero se trata de un entusiasmo meramente verbal. A la opinión pública le es indiferente lo que pasa realmente en África y Asia, ya que sus puntos de orientación y sus valores normativos - como también sus fobias y aversiones-están determinados, de manera casi absoluta, por lo que ocurre en los Estados Unidos y particularmente en Miami. Hechos recientes y dramáticos en otros continentes, como las matanzas de Ruanda, el surgimiento de nuevas naciones (por ejemplo Eritrea y Somalilandia), la curiosa guerra tribal en Somalia, la restauración de la monarquía en Cambodia,

* Universidad Mayor de San Andrés, La Paz, Bolivia. el éxito de la democracia liberal en Oceanía (desde Papúa Nueva Guinea hasta Samoa), las brutalidades del régimen nacional-socialista en Birmania o la reunificación violenta del Yemen no perturban el sueño de nadie. No es del todo superfluo, empero, el preocuparnos por lo que sucede en aquellos ámbitos exóticos, debido a que vivimos en un mundo cada vez más pequeño y mejor intercomunicado, donde cualquier acontecimiento en lejanas tierras puede influir sobre nuestros decursos evolutivos.

El desarrollo del mundo islámico nos debería concernir por varias razones. Compartimos, aunque sea de modo diluido, un legado cultural y hasta racial muy importante, heredado mediante la colonización ibérica. Dos factores centrales de la cultura árabe-islámica no han sido ajenos a nuestra idiosincrasia: 1) la inclinación al dogmatismo, es decir a presu- 
NOTAS

poner la existencia de una sola verdad en la esfera de la religión, la ideología y las convicciones, y 2) la tendencia a no separar la esfera religiosa de la mundana (o la privada de la pública), lo que es desfavorable a la moderna diferenciación de roles y actitudes. El área musulmana es hasta ahora pobre en experimentos exitosos de democracia pluralista y de economía de mercado. Prevalece aún el sistema de partido único y el régimen caudillista habitual. El respeto a las propias minorías étnicas y lingüísticas - para no mencionar obviamente las religiosas - es muy exiguo, como lo atestiguan los casos Irak, Irán, Sudán, Turquía, Siria y Líbano. Desde Senegal hasta Indonesia hay sólo dos países con estructura federal: Pakistán y Malaysia. Subsisten estados sin constitución escrita (como Arabia Saudita), sin parlamentos dignos de tal nombre (la mayoría de los casos) y sin prensa libre (Egipto es una de las poquísimas excepciones). La validez de los estatutos legales se circunscribe a la mera teoría.

Los últimos tiempos han traído consigo un desarrollo lleno de traumas para el ámbito islámico. El derrumbe de arraigadas ideologías convencionales, el colapso del otrora tan sólido sistema socialista — por el cual siempre existió la más amplia simpatía en los países árabes-y la con- moción del orden tradicional por efecto de la exitosa cultura occidental del consumismo masivo, han suscitado en el mundo musulmán un vacío de valores de orientación. De aquí se nutren iniciativas violentas y caóticas; se acrecienta la tentación del encierro en sí mismo, pero igualmente la inclinación a combatir lo Otro, presunta encarnación del mal y de las propias dificultades. El hallar a los chivos expiatorios no es entonces tarea difícil: el fundamentalismo islámico los ha encontrado en los diablos occidentales.

Lo novedoso de la situación contemporánea parece residir en una curiosa amalgama entre una defensa de la propia tradición cultural (percibida en estado de máximo peligro) y una apropiación acrítica de los elementos técnico-económicos de la civilización industrial de Occidente. No pocos socialistas y revolucionarios, que se quedaron sin trabajo y sin ideas, se dedican ahora a fomentar credos religiosos fundamentalistas, inclinaciones particularistas de toda laya y designios reivindicatorios de minorías étnicas, junto con los nacionalismos más delirantes, como ocurre en Argelia, Asia Central, el Cáucaso, Sudán y Afganistán. Ahora bien, hasta cierto punto es comprensible la actitud de fundamentalistas y nacionalistas. En una época de fronteras permeables, de un sistema 
global de comunicaciones casi totalmente integrado y de pautas normativas universales, nace la voluntad de oponerse a las corrientes de uniformamiento y despersonalización. Sin embargo, la legítima aspiración de afirmar la propia identidad sociocultural puede transformarse rápidamente en una tendencia xenófoba, racista, agresiva, demagógica y claramente irracional, que a la postre pretende la aniquilación del Otro. Esta actitud entraña, como escribió Federico Mayor Zaragoza, una negación de los valores universales, un menosprecio de los derechos y libertades de la persona, un repudio a todo diálogo y a todo esfuerzo de educación para la tolerancia.

En el ámbito islámico se extiende ahora la opinión de que los derechos humanos, la filosofía racionalista, la ética del respeto liminar al individuo y las instituciones de la democracia occidental conformarían parte integrante de una inaceptable doctrina universalista, la que, a su vez, sería una forma encubierta de eurocentrismo y, por consiguiente, un instrumento de dominación cultural. No hay duda de que porciones centrales de estos fenómenos se han originado en el Occidente europeo y que a menudo han sido utilizados para justificar y consolidar un predominio imperial. Las facultades - 0 , si se quiere, las pretensiones - universalistas del racionalismo europeo no han sido, empero, los factores causales de procesos como la cultura política del totalitarismo político, la trata de esclavos, el saqueo de los recursos naturales y el exterminio de los propios aborígenes, procesos muy comunes en los países musulmanes y que han tenido una historia más ántigua y un alcance geográfico más dilatado que la moderna civilización europea occidental. Es claro que toda teoría con aspiraciones de generalidad y obligatoriedad concita reacciones hostiles; una ética de derecho universal, como la contenida en la concepción actual de los derechos humanos, es considerada como una máscara del imperialismo eurocentrista, y simultáneamente como un solapado y peligroso ataque a las propias tradiciones autóctonas.

El rechazo del universalismo a causa de su presunto carácter eurocéntrico o su talante imperialista se conjuga con la búsqueda de una identidad cultural o nacional primigenia, que estaría en peligro de desaparecer ante el avasallamiento de la moderna cultura occidental de cuño globalizador. Esta indagación, a veces dramática y a menudo dolorosa para las comunidades musulmanas, intenta develar y reconstruir una esencia étnica, cultural, linguística o histórica que confiera características indelebles y, al mismo tiempo, totalmente 
originales a las comunidades islámicas contemporáneas. Este esfuerzo puede ser calificado de traumatizante y de inútil: los ingredientes aparentemente más sólidos y los factores más sagrados del acervo cultural e histórico de los pueblos musulmanes resultan ser una mixtura deleznable $y$ contingente de elementos que provienen de otras tradiciones nacionales o que tienen una procedencia común con los más diversos procesos civilizatorios. Son indudables los efectos negativos y hasta devastadores que de algún modo pueden ser asociados a la moderna lógica occidental, cuya aplicación en los países musulmanes ocurre habitualmente sin sus principios humanistas y sin su talante escéptico y autocrítico, lo que se manifiesta claramente en los desarreglos ecológicos que dimanan del intento de dominar y explotar hasta el último rincón de la Tierra. Pero aquella lógica ha producido igualmente los derechos humanos, la democracia pluralista y la concepción del respeto a las minorías; los grupos étnicos situados o mantenidos en una situación socio-económica discriminatoria comienzan a darse cuenta de las manifiestas ventajas que conlleva el universalismo occidental para defender sus intereses y acrecentar su participación en los usualmente magros frutos del crecimiento técnico-económico. Éste es claramen- te el caso de las minorías de todo tipo que tienen que soportar las consecuencias del integrismo más radical, como se da actualmente en Persia, Sudán e Irak.

En las comunidades islámicas ortodoxas el Estado posee una dignidad superior a la del individuo; éste existe sólo en y para la colectividad. Derechos humanos, instituciones autónomas al margen del Estado omnímodo y mecanismos para controlar y limitar los poderes del gobierno son considerados, por lo tanto, como opuestos al legado coránico y llevan una existencia precaria. El comportamiento adecuado a tales circunstancias es el total sometimiento (lo que es el significado literal de Islam) a las autoridades temporales y espirituales, complementado por un quietismo intelectual bastante estéril. El desenvolvimiento del individuo en un ámbito liberado de la influencia perniciosa del Estado y protegido por estatutos legales fue totalmente desconocido en el mundo islámico hasta la introducción parcial de la legislación europea. Por ello es un hecho generalizado que hasta hoy el rol de los derechos humanos y políticos sea marcadamente secundario, que la división de los poderes estatales y el mutuo control de los mismos permanezcan una ficción, que el régimen de partido único goce de excelente reputación y que la autoridad supre- 
NOTAS

ma tienda a ser caudillista, carismática e ilimitada. Todos estos elementos tienden a reforzar un monismo liminar: una sola ley, un único modelo de reordenamiento socio-político, una cultura predominante, una estructura social unitaria y, como corolario, una voluntad general encarnada en el gobierno de turno. Este sistema, que confunde aclamación con participación popular y la carencia de opiniones divergentes con una identidad colectiva sólida y bien 1ograda, corresponde, en el fondo, a un estadio evolutivo inferior y superado por la historia universal. Pero aún sin apelar a teorías evolutivas historicistas - que son una especialidad de la filosofía occidental y muy probablemente una justificación sesgada del desarrollo de Europa - se puede llegar a la conclusión de que la civilización islámica destruyó mediante su primera y muy exitosa expansión militar una pluralidad de culturas (la persa, las variantes bizantinas en Asia y África, las comunidades árabes preislámicas, las culturas autóctonas del Asia Central y otras), que habían alcanzado importantes logros civilizatorios propios, soluciones originales en la superación de problemas económicos, institucionales y organizativos y una brillantez inusitada en los campos del arte y la literatura. Para estos ámbitos la cultura islámica trajo consigo un retorno a modelos socio-culturales arcaicos, adoptados, como se sabe, de una sociedad protourbana de beduinos, rodeada del medio hostil y aislante del desierto. Los defensores actuales del autoctonismo árabe-islámico olvidan que éste no es precisamente creación auténtica, libre y realmente aborigen de muchos pueblos del norte de África, así como del Cercano y Medio Oriente.

Contra los ideólogos del particularismo islámico se puede aducir que esta tradición propugna también la validez universal de sus principios, normas y valores de orientación, y de un modo bastante imperioso, cuando no despótico; que la historia de esta cultura está plagada de atropellos de todo tipo cometidos contra otros pueblos; y que la absoluta predominancia de la fe religiosa, que ha impregnado todo aspecto de la vida civil, no es favorable ni a un proceso más o menos autónomo de modernización ni a la comprensión de las otras comunidades (y, sobre todo, de sus singularidades) a nivel mundial.

El fundamentalismo islámico, sobre todo en sus variantes persa, sudanesa y argelina, exhibe una marcada negligencia con respecto al individuo y sus derechos pre-estatales: con el popular argumento de cimentar la unidad de la nación, cohesionar el cuerpo social y unir todas las energías en pro de un desarrollo acelerado, los 
ideólogos de la liberación anti-imperialista han desempolvado ese legado indígena de colectivismo totalitario y lo han utilizado eficazmente luego de la independencia del Estado respectivo para acallar toda crítica al gobierno nacionalista o progresista, para impedir la formación de cualquier oposición política y, paradójicamente, para suprimir toda tendencia regionalista o étnico-cultural (es decir: eminentemente particularista) dentro del nuevo país.

En muchos países musulmanes las relaciones interhumanas estriban en un modelo de connotaciones racistas y místico-nacionales, modelo que presupone la fusión colectiva de las voluntades (preconscientes); la concepción de un contrato voluntario y surgido de una decisión libre y democrática ha jugado un papel muy limitado en la constitución de los nuevos estados. Este marco de referencia no deja mucho espacio a los derechos individuales, a la propiedad privada, al cosmopolitismo y al pluralismo contemporáneo. El fundamento étnico-cultural de un Estado engendra un instrumentario ideológico y hasta material que puede ser usado para reprimir cualquier etnia menor que se sienta discriminada o cualquier idea o corriente política que parezca incómoda a los ojos de los nuevos gobernantes. Es comprensible que los llamados 'movimientos de liberación nacional' de orientación islámica fundamentalista - como en Argelia, Yemen, Sudán, Irak, Eritrea y Somalilandia - hayan elegido el principio de la identidad étnico-cultural (conservador y hasta reaccionario) como fundamento de los nuevos estados y no la noción liberal del plebiscito cotidiano o la asociación voluntaria laica de los ciudadanos consultados previamente. La concepción de negociaciones voluntarias y surgidas de una decisión libre y democrática ha jugado un papel muy limitado en la política cotidiana de las naciones musulmanas. Este marco de referencia no deja mucho espacio a los derechos individuales, a la propiedad privada, al cosmopolitismo y al pluralismo contemporáneo. $\mathrm{El}$ rechazo de los valores y las metas universalistas es una típica actitud intelectual que emerge recién después de una relación extensa, ambigua y traumática con una cultura triunfante en los campos económico, tecnológico y político, y cuando una porción considerable de la propia población - empezando por las élites-adopta ostentativa e inequívocamente las pautas de orientación de las sociedades reputadas como superiores. A éstas se les atribuye precisamente el carácter de lo universal y de aquello avalado por el progreso histórico. Pero las capas y los grupos sociales que no han sido beneficiados de este 
NOTAS

proceso - y muy especialmente sus intérpretes intelectuales- perciben todo esto como una traición a la esencia peculiar de aquella nación en condiciones de inferioridad, como una defección de sus auténticas metas civilizatorias y como un abandono de sus tradiciones más sagradas. La reconquista de la identidad y de sus rasgos particulares resulta ser a la postre una ideología convencional, una racionalización de otra intención muy comprensible: el hacer pasar un modelo híbrido de desarrollo como si fuese la continuación o el renacimiento de un venerable legado histórico, soterrado momentáneamente por la agresión imperialista en connivencia con la reacción local. El régimen del integrismo islámico no es obviamente un simple retorno al pasado y a sus valores identificatorios particularistas. Esta "cultura a la defensiva" (como la designó el brillante analista sirio Bassam Tibi) pretende una síntesis entre el desarrollo técnicoeconómico moderno y la civilización tradicional en los campos de la vida familiar, la religión y las estructuras socio-políticas. Es decir, acepta de manera totalmente acrítica los últimos progresos de la tecnología, los armamentos, los sistemas de comunicación más refinados provenientes de Occidente y sus métodos de gerencia empresarial, por un lado, y preserva, por otro, de modo igual- mente ingenuo, las modalidades de la esfera íntima, las pautas colectivas de comportamiento cotidiano $\mathrm{y}$ las instituciones políticas de la propia herencia histórica conformada antes del contacto con las potencias europeas. La consecuencia de estos procesos de aculturación, que siempre van acompañados por fenómenos de desestabilización emocional colectiva, se traduce en una irritante mixtura de a) una extendida tecnofilia en el ámbito económico-tecnológico, con b) la conservación de modos de pensar y actuar premodernos, particularistas (en sentido negativo) y francamente retrógados en los otros campos de la vida humana. El resguardar y hasta consolidar la tradición socio-política del autoritarismo tiene entonces la función de proteger una identidad colectiva en peligro de desaparecer (barrida por los valores universalistas propagados por los medios contemporáneos de comunicación), de hacer más digerible la adopción de parámetros modernos en otras esferas de la actividad social, y mantener un puente entre el acervo cultural primigenio y los avances de una modernización considerada como inevitable.

A lo largo de la historia universal han existido muchos intentos de legitimizar estos regímenes híbridos y esta aceptación parcial y parcializante de la civilización occidental. Ya en 
la China de comienzos del siglo XIX se hacía una diferencia entre la religión, la cultura, la filosofía y la politica de los 'bárbaros' occidentales, por un lado, y sus técnicas militares e industriales, por otro. La misma actitud fue frecuente durante el primer intento de modernización en el mundo árabe, en el Egipto del siglo XIX bajo el despotismo ilustrado de Mehemet Alí. Lo primero debía ser rechazado tajantemente, pues era el núcleo de una sociedad aborrecible, pero lo segundo constituía lo 'aprovechable' de la misma, que podía ser utilizado sin contaminar la identidad de la cultura endógena. El resultado es una modernidad imitativa, que adapta más o menos exitosamente algunos técnicode la sociedad industrial moderna, que pueden ser resumidos bajo la categoría de una racionalidad meramente instrumental. Pero sus otros grandes logros, que van desde la democracia parlamentaria hasta el racionalismo y la ética basada en el humanismo y la tolerancia, son escamoteados discretamente o rechazados con inusitada vehemencia, como en los casos del fundamentalismo islámico contemporáneo. 